\title{
MULHER E AUTORREGULAMENTAÇÃO PUBLICITÁRIA: ANÁLISE DOS PROCESSOS NO CONAR
}

\author{
Women and advertising self-regulation: Analysis of complaints in Conar
}

Mujer y autorregulación publicitaria: análisis de denuncias en Conar

Luana Ferreira Alves

Mestre em Comunicação pela Universidade de Brasília (UnB) e Analista de Projetos do Fundo Social ELAS

ferreiraluana44@yahoo.com.br

Sivaldo Pereira da Silva

Professor da Faculdade de Comunicação e do Programa de Pós-Graduação em Comunicação da Universidade de Brasília (UnB) sivaldop@unb.br

\section{Resumo}

O presente artigo visa caracterizar os processos de denúncias julgados pelo Conar que tratam de possíveis violações contra mulheres em propaganda no Brasil. Foram analisados 63 processos do Conselho resultantes de uma amostra de 4 anos, coletada entre 2006 e 2016. Utilizou-se instrumentos metodológicos como (a) Pesquisa documental; (b) Planilha estruturada de coleta de dados; (b) Análise de conteúdo. Os resultados demonstram que a TV é o meio mais citado nos processos, seguida pela internet. Os dados demonstraram um maior volume de denúncias nos anos mais recentes. Bebidas alcoólicas, Automobilístico e Alimentício são responsáveis por quase a metade das denúncias e oito empresas/ marcas estão presentes em quase $60 \%$ dos processos. Os julgamentos de processos por conselheiros homens ou mulheres demonstram tendências distintas.

Palavras-chave: Conar. Propaganda. Mulher.

\begin{abstract}
This article aims to characterize the complaints judged by Conar that deal with possible violations against women in Brazilian advertising. We analyzed 63 requests for judgment resulting from a 4-year sample, collected between 2006 and 2016. We use methodological instruments such as (a) Documentary research; (b) Data Collection Worksheet ; (b) Content analysis. The results demonstrate that the most frequent media mentioned is TV, followed by the internet. There has been a greater number of complaints in recent years. Products such as alcoholic beverages, automobiles and food are present in about $50 \%$ of complaints. A group composed of 8 companies / brands are present in almost $60 \%$ of the analyzed documents. Judgments made by male or female counselors show different trends.o.
\end{abstract}

Key words: Conar. advertising. women. 


\section{Resumen}

Este artículo tiene como objetivo caracterizar los procesos de denuncia juzgados por Conar que tratan con posibles violaciones contra las mujeres en publicidad en Brasil. Se analizaron 63 procesos del Consejo resultantes de una muestra de cuatro años recolectada entre 2006 y 2016. Se utilizaron instrumentos metodológicos como (a) Investigación documental; (b) Formulario para la recolección estructurada de datos; (b) Análisis de contenido. Los resultados muestran que la televisión es el medio más citado en el proceso, seguido de Internet. Hay un mayor volumen de quejas en los últimos años. Las bebidas alcohólicas, automotriz y alimentaria son responsables de casi la mitad de las quejas y ocho empresas/ marcas están presentes en casi el $60 \%$ de los casos. El juicio de casos por consejeros masculinos o femeninos muestra tendencias distintas.

Palabras clave: Conar. Publicidad. Mujer.

\section{INTRODUÇÃO}

A produção do sentido de realidade, de símbolos culturais e valores sociais está inevitavelmente vinculada aos processos de comunicação e isso se torna cada vez mais forte em sociedades midiatizadas. Não é por acaso que a ideia de propaganda visa "propagar" ideias e concepções, enquanto uma prática que tende produzir narrativas que, em última instância, também afeta as relações de poder. Desde a emergência de um sistema de comunicação de massa que se iniciou com o impresso e depois foi se ampliando com a chegada do rádio, da TV e, mais recentemente, da Internet, o papel e a importância da publicidade e propaganda tem se intensificado, fazendo parte do tecido cultural contemporâneo. Na busca desenfreada por novos consumidores, as agências de publicidades (através dos meios de comunicação) reproduzem preconceitos, fortalecendo crenças discriminatórias e violentas, que afetam a forma como a sociedade vê diferentes grupos sociais.

A relação entre mulher e mídia tem sido objeto de estudo a partir de diversos enfoques (BELELI, 2007; MORENO, 2012; AMARAL; COIMBRA， 2015; GUIMARÃES; OLIVEIRA, 2015; MANO, 2017; GONZALEZ, HASENBALG, 1982). Esses estudos têm demonstrado que a vinculação do feminino ao "doméstico" ou o tratamento do corpo da mulher como um objeto de desejo e de consumo vinculado a marcas e produtos não são apenas estratégias comerciais inócuas: tem um importante efeito social, seja colocando a mulher fora do espaço público, seja tornando-a objeto de violências simbólicas e físicas.

Diante deste cenário, o presente artigo trata de compreender como o Brasil vem tratando essas questões do ponto de vista regulatório. No país, a propaganda não é regulada 
diretamente por um órgão governamental (como ocorre em outras áreas da comunicação social, a exemplo da radiodifusão ou Internet) e sim por um mecanismo de autoregulamentação, o Conar (Conselho Nacional de Autorregulamentação Publicitária).

A proposta geral desta pesquisa é caracterizar as denúncias e os processos julgados pelo Conar e que tratam de tipos de violações contra a imagem das mulheres nas veiculações de propaganda e publicidade no Brasil. Neste sentido, foram analisados os processos registrados em quatro anos (2006, 2007, 2015 e 2016) colhendo assim uma amostra representativa de um intervalo de tempo de 10 anos, totalizando 63 processos.

Para alcançar os objetivos propostos, o artigo está dividido em duas partes subsequentes. Primeiramente, discutiremos bases conceituais que envolvem o conceito de "gênero" e alguns aspectos das teorias de estudos feministas, levando isso para o campo da comunicação, especificamente da publicidade. Em seguida, serão apresentados os resultados de pesquisa que analisou os processos que envolvem denúncias de propagandas sobre mulheres no Conar, buscando compreender suas características, andamento e desfecho.

\section{GÊNERO, MULHER, TEORIAS FEMINISTAS E O PAPEL DA COMUNICAÇÃO}

Para perceber as nuances das relações de gênero, na perspectiva da construção das visões hegemônicas de vivências masculinas e femininas, a historiadora e feminista estadunidense Joan Wallace Scott (1986) define gênero como "um elemento constitutivo de relações sociais baseadas nas diferenças percebidas entre os sexos, e é uma forma primária de significativas relações de poder" (SCOTT, 1986, p. 1067). Gênero refere-se a uma categoria social que institui as concepções de masculino e feminino, nas quais os seres humanos são classificados tendo por referência o sexo biológico (LAURETIS, 1994), que também é culturalizado e discursivamente elaborado. Neste sentido, como uma possibilidade de interpretação do mundo, em suas relações de poder, o feminismo associa o ativismo pela igualdade de gênero, ao compromisso da investigação relativa às causas e aos mecanismos de reprodução da dominação masculina nas sociedades contemporâneas.

A construção discursiva do gênero na publicidade reforça o poder atravessado de violência contra os corpos e a psique das mulheres. E é a partir dos movimentos sociais dos anos 1960 e 1970 que está situada boa parte da origem de pesquisas de múltiplas áreas dos estudos de gênero, empreitadas por feministas de diversas áreas do conhecimento, no intuito 
de romper este discurso frágil, reforçado pela heterossexualidade compulsória. Segundo Navarro-Swain (2010):

A heterossexualidade compulsória é, assim, uma instituição política com todas as variáveis que isso implica, na importância social, na estrutura de empregos, na divisão do trabalho e sua remuneração, no sistema produtivo em geral, nas esferas administrativas das empresas públicas e privadas, no governo e nas relações sociais de modo geral, em que o masculino é mais valorizado do que o feminino. (NAVARRO-SWAIN, 2010. p. 48).

A construção do gênero, como categoria política de reivindicação do debate sobre atuações das mulheres nos âmbitos público e privado (ELSHTAIN, 1981; CORNELL, 1998; PATEMAN, 2013) - em detrimento das argumentações e construções sociais baseadas no sexo biológico- tem a proposta política de trazer à luz as distinções e desigualdades que compõem as feminilidades e masculinidades em toda a complexidade das relações sociais. Sobre as influências de tais elaborações e inquietações sociais, segundo Knoll (2012):

O conceito de gênero surgiu como produto das teorias feministas. Os movimentos feministas remontam a várias épocas e lugares: à França do século XVIII, durante a Revolução Francesa, em que Olympe de Gouges escreveu a Declaração dos Direitos das Mulheres e da Cidadã (1791), argumentando que os direitos dos homens também pertenciam às mulheres; aos Estados Unidos do século XIX, com o primeiro movimento oficialmente organizado; à Inglaterra de 1919, com a grande mobilização das sufragistas inglesas. Contudo, foi nos anos 60 e 70 que eclodiram os movimentos mais expressivos nos Estados Unidos, na Inglaterra e na França, que, mais tarde, espalharam-se pelo mundo (KNOLL, 2012, p. 240).

No desafio do debate, se insere a importância de reconhecer significados atribuídos aos corpos, ao gênero e ao sexo que estão nas repetições cotidianas socioculturais hegemônicas com intrínsecas e específicas significações culturais. Como discute (BUTLER, 2003, p. 27 - 28), o discurso busca estabelecer limites, em que o gênero e o sexo fixos ou livres, aparecem com significados da referência de quem o profere, com indicações das possibilidades culturais prováveis de serem mobilizadas por meio de quaisquer análises posteriores.

Sobre reações e possibilidades para experiências subversivas às práticas que incentivam desigualdades nos comportamentos tidos como oficiais entre homens e mulheres, Biroli e Miguel (2013), apontam que: 
Um pensamento, para se caracterizar como feminista, não se limita a afirmação literária da igualdade de talentos ou de valor entre mulheres e homens, nem a reivindicação política da extensão dos direitos individuais a toda a espécie humana. $\mathrm{O}$ feminismo se definiu pela construção de uma crítica que vincula a submissão da mulher na esfera doméstica a sua exclusão da esfera pública. Assim, no mundo ocidental, o feminismo, como movimento político e intelectual, surge na virada do século XVIII para o século XIX e pode ser considerado um filho indesejado da Revolução Francesa (BIROLI; MIGUEL, 2013, p.8).

Conquistas de emancipação para as mulheres e experiências ancoradas no ideal de igualdade e fraternidade, como uma "crença" de séculos, têm sido cada vez mais questionadas e enfraquecidas, diante da realidade que vivem as mulheres nas relações sociais no ocidente.

$\mathrm{Na}$ perspectiva de que novos esforços devem vir em cena, em favor de uma comunicação mais comprometida com igualdade de direitos, compreender que existe uma postura dominante do discurso de objetificação das mulheres na sociedade contemporânea é mais que uma opção, se faz um ponto de debate. Segundo Tiburi:

Talvez não tenha sido percebido ainda que o autoritarismo (como centralidade da autoridade), seja mais do que uma postura, ele é essencialmente um regime de pensamento. Uma operação mental que, em sentido amplo, se torna paradigmática agindo sobre a ciência, a cultura e o senso comum. O autoritarismo como regime de pensamento poderia ser superado por aquilo que podemos chamar de paradigma do pensamento democrático (TIBURI, 2015, p. 25).

\section{Conforme a 62 $2^{\mathrm{a}}$ Sessão da Comissão da ONU sobre a Situação das Mulheres (CSW} 62), ocorrida em Nova Iorque, em março de 2018, o avanço e o empoderamento das mulheres na participação e acesso delas à mídia e às tecnologias da informação e comunicação são necessidades ainda descobertas. Nesta mesma sessão, a presidenta da Federação Nacional dos Jornalistas, Maria José Braga, afirma:

Continuam sendo coisificadas, em pleno século XXI. E os meios de comunicação de alguma forma têm que ser responsabilizados por essa objetificação que fazem da mulher, mais nitidamente ainda na publicidade. Também precisamos tratar da grave ausência das questões de interesse das mulheres como pauta jornalística, que não devem aparecer apenas no mês de março, e também da quase inexistência de mulheres como fontes ${ }^{1}$.

Ao adentrarmos o ambiente cultural e publicitário, enquanto repetição de padrões, é possível perceber diversos mecanismos de exploração da mulher. $\mathrm{O}$ corpo feminino é visto

\footnotetext{
${ }^{1}$ Disponível em : https://www.geledes.org.br/comunicacao-e-direito-essencial-para-o-empoderamento-dasmulheres-destacam-brasileiras-sobre-tema-emergente-mulheres-e-midia-na-csw-62/. Acesso 21 março 2019.
} 
como elemento de estratégia de consumo, tanto em anúncios publicitários (veiculados nos intervalos de programas televisivos e radiofônicos ou em páginas de revistas e jornais impressos ou sites na Internet) como também no interior dos próprios conteúdos produzidos pelos meios de comunicação (novelas, reality shows, telejornais, programas de auditório, textos e imagens em mídias sociais etc.).

A perpetuação destas veiculações tem claramente um potencial lesivo quando geram uma objetificação da existência feminina, em nossa sociedade, por ganhar dimensões e desdobramentos nos comportamentos de crianças, jovens e adultos. Isso influencia diretamente a formação moral e intelectual de uma sociedade e tende a culminar, não apenas em violências simbólicas, mas também em violências físicas pois cristalizam premissas que fazem enxergar as mulheres apenas corpos cuja única finalidade é dar prazer aos homens, incentivando, assim, uma cultura machista que tem seus efeitos reais e danosos na vida pública e privada.

A estratificação desse mecanismo de dominação tem efeitos drásticos nas vidas das mulheres, de todas as camadas econômicas da sociedade, independentemente de serem urbanas ou não, pois o peso de reduzir a dignidade da mulher, a transformando em mero objeto, facilita a adoção de práticas de exploração das mesmas. Para Scheidweiler e Sousa (2017):

[...] a garantia necessária para que homens e mulheres possam falar, escrever e imprimir livremente, sob qualquer meio, como definem os documentos internacionais relacionados aos direitos humanos, ficou ainda mais complexa com o surgimento das comunicações eletrônicas, em especial o rádio e da televisão, que sempre foram controlados por conglomerados comunicacionais que, em sua maioria, operam a partir de uma lógica econômica e majoritariamente masculina. (SCHEIDWEILER \& SOUSA, 2017, p.03)

No sentido de colaborar para uma sociedade mais justa e igualitária, entender que existem condições que limitam e até impossibilitam a atuação de mulheres na esfera pública, potencializa as dimensões de desenvolvimento econômico, social e político das relações sociais. Scheidweiler e Sousa (2017) também afirmam que "assumir que relações desiguais de poder causam prejuízo à autonomia das mulheres é o primeiro passo (p. 04)”.

No Brasil, a ampliação do debate sobre violências contra mulheres tem sido fortalecida desde a década de 1980, quando as universidades brasileiras, sob influência norte-americana de estudos do gênero, incorporaram a investigação científica sobre a violência doméstica contra mulheres. Segundo Bruna Pereira (2016): 
O envolvimento com atividades da Década da Mulher promovida pela Organização das Nações Unidas (ONU) (1976-1985), os Encontros Feministas Latino-Americanos e do Caribe iniciados na década de 1980, as articulações formadas para atuação nas Conferências da ONU a partir dos anos 1990, a experiência de atuação durante a Assembleia Constituinte (19871988) e as diversas edições da Conferência Nacional de Política para Mulheres (2004, 2007 e 2011), bem como a produção acadêmica daí decorrente, proporcionaram aos movimentos feministas e de mulheres a consolidação de amplo material discursivo, acúmulo político e conhecimento técnico sobre a incidência deste tipo de violência. (PEREIRA, 2016, p. 25)

Para entendermos a construção social sobre o imaginário relacionado ao gênero feminino em nossa sociedade devemos pensar na relação entre os vários tipos de violência que envolvem a perspectiva de gênero (SAFFIOTI, 2001; SOIHET, 2009). Na publicidade, isso também se traduz em diversas formas e as deficiências do atual modelo brasileiro de regulamentação da propaganda apontam para a tendência de reforço das crenças sociais de submissão e objetificação das mulheres em relação aos homens. Isso acontece tanto por parte de peças publicitárias quanto nos perfis de muitas das decisões do Conar, em relação às queixas e denúncias referentes a elas, como veremos.

Permeando cada vez mais as vidas das pessoas, a propaganda e publicidade têm se tornado um importante objeto de debate e críticas. Com muita frequência, caracteriza de modo ofensivo alguns grupos sociais, expondo-os a situações de desvantagem em relação a outros, incentivando discursos violentos. $\mathrm{E}$ isso também vem ocorrendo no modo de tratar a imagem das mulheres que, na prática, tecem a forma como estas são vistas numa realidade cultural construída por narrativas midiáticas que tem seus efeitos colaterais reais, consumados nas diversas formas de violência hoje vigentes.

E ainda sobre modos de dominação, não é possível ignorar que a mercantilização dos corpos acentua que corpo é consumível e qual é dispensável. Por exemplo, os estereótipos negros que fazem parte do imaginário racialmente dominante, também precisam de avaliação sobre as relações raciais no discurso que diferencia um tipo de corpo, como inferior (GONZALEZ; HASENBALG, 1982).

\section{DENÚNCIAS JULGADAS PELO CONAR: CARACTERÍSTICAS, ANDAMENTO E DESFECHO DOS PROCESSOS}

No Brasil as políticas públicas e a regulação da Comunicação Social, enquanto atividade industrial, é bastante frágil com diversas leis e normas infra-legais fragmentadas e 
não sistemáticas, com vários órgãos atuando em segmentos específicos e quase sempre com baixo poder de enforcement real. Neste cenário, também está o campo da publicidade e propaganda que não possui uma agência própria em termos de regulação e sim um órgão de autorregulamentação, o Conselho Nacional de Autorregulamentação Publicitária (Conar).

O Conar foi criado em 1980 após a aprovação do Código Brasileiro de Autorregulamentação Publicitária (CBAP), em 1978. Na década de 1970, com a presença gradativa dos movimentos sociais de defesa dos consumidores, começaram a incidir sobre iniciativas governamentais de regulação da propaganda comercial. Em meio à ditadura militar, o governo tentou sancionar uma lei de censura à propaganda, instituindo um órgão de controle prévio dos anúncios. Publicitários, anunciantes e veículos apresentaram então o Código Brasileiro de Autorregulamentação Publicitária (CBAP) cujo propósito seria zelar pela liberdade de expressão comercial e defender os interesses de todas as partes envolvidas no mercado, inclusive consumidores. O Conar, organização não governamental formada por entidades do mercado publicitário brasileiro, é responsável pelo cumprimento do CBAP. Recebe denúncias de consumidores (as), autoridades, associados (as) e de sua própria diretoria. Dentro da estrutura do Conar, o Conselho de Ética é o órgão responsável pela fiscalização e julgamento referentes ao cumprimento do Código. Por não ser órgão estatal, o parecer emitido pelo Conar sobre o julgamento de peças publicitárias apenas apresenta recomendações pois não tem o poder de polícia. Mas é respeitado pela maior parte de entidades e empresas, que seguem tais recomendações, independentemente de serem agências, veículos ou anunciantes.

Para compreender e problematizar as características do julgamento de discursos publicitários, na relação entre comunicação e violência contra o feminino e o papel do Conar, foram analisados 63 processos referentes às representações de denúncias e queixas relacionadas a violências contra mulheres na publicidade nos anos 2006, 2007, 2015 e 2016. A escolha deste recorte temporal teve como objetivo obter uma amostra significativa capaz de representar um conjunto de processos num período de 10 anos (2006 a 2016), colhendo dados de biênios mais antigos e mais recentes neste intervalo de tempo.

A partir desta definição do recorte foram triangulados os seguintes instrumentos metodológicos para coleta, tratamento e análise dos dados: (a) Pesquisa documental (processos do Conar sobre denúncias que envolviam a imagem da mulher); (b) Planilha estruturada de coleta de dados (com variáveis quanti-qualitativa aplicáveis aos textos dos 
processos); (b) Análise de conteúdo (para viabilizar uma melhor compreensão qualitativa dos dados coletados).

A primeira etapa deste estudo consistiu em mapear as denúncias julgadas, pelo Conar, disponíveis no site do Conselho, contidas na aba Casos - Decisões - Respeitabilidade. A partir de constatação de irregularidades na disponibilização de alguns dados e da ausência de outros, foram feitos contatos via e-mail e via ligação telefônica, com o Conselho, culminando em visita física à sede do mesmo, localizado na cidade de São Paulo para posteriormente acessar os arquivos digitais disponibilizados via acesso remoto.

$\mathrm{Na}$ organização e cruzamento dos dados, foi desenvolvida uma planilha eletrônica estruturada e alimentada com informações dos 63 processos. Isso incluiu dados sobre os agentes envolvidos nas decisões; a identificação tanto de quem se queixa, quanto da defesa e do julgamento; as argumentações referentes aos casos julgados; e ainda a contextualização das denúncias, dentre outras questões interseccionais possíveis. Também aplicamos qualificações próprias sobre os dados, tipificando os denunciantes, as empresas e os argumentos contidos nos processos.

Para descrever os resultados da pesquisa, trataremos a seguir três conjuntos de elementos que consideramos fundamentais para compreender as características da atividade de autorregulação publicitária no Brasil no tocante ao tema da mulher e propaganda. Primeiramente, trataremos das características das denúncias, onde será possível observar as demandas apresentadas ao Conselho; seus aspectos motivadores e argumentos levantados; perfis de denunciantes e denunciados e outros cruzamentos relevantes. Segundo, traremos dados e análises sobre as características de tramitação, onde abordaremos mecanismos vinculados ao andamento dos processos; aspectos organizacionais e funcionais relevantes. E, por fim, analisaremos as características do julgamento e seus resultados, buscando compreender o desfecho dos processos; penalidades aplicadas; se há padrões relevantes entre denúncias acatadas e denúncias arquivadas.

\subsection{Características das denúncias}

O primeiro elemento analisado trata da caracterização das razões que suscitaram as denúncias. As justificativas levantadas pelos denunciantes que mais aparecem nos processos são "Conteúdo deseducativo e desrespeitoso" (citada em quase $72 \%$ dos processos); "Associação inadequada sobre mulheres" (citada em 52\% dos processos); "Apelo excessivo à 
sensualidade" e "Incentivo ao comportamento machista" (cada uma presente em cerca de 40\%); “. Na tabela 1 temos um detalhamento sobre esses argumentos mais mencionados pelos denunciantes.

Tabela 1 - Justificativas das denúncias mais recorrentes nos processos

\begin{tabular}{|l|c|c|}
\hline \multicolumn{1}{|c|}{$\begin{array}{c}\text { Base argumentativa } \\
\text { da denúncia }\end{array}$} & $\begin{array}{c}\text { Quant. de processos } \\
\text { nos quais a denúncia } \\
\text { aparece }\end{array}$ & $\begin{array}{c}\text { Percentual dos } \\
\text { processos nos quais } \\
\text { a denúncia aparece }\end{array}$ \\
\hline Conteúdo deseducativo e desrespeitoso & 45 & $71,0 \%$ \\
\hline Associação inadequada sobre mulheres & 33 & $52,4 \%$ \\
\hline Apelo excessivo a sensualidade & 25 & $39,7 \%$ \\
\hline Incentivo ao comportamento machista & 24 & $38,0 \%$ \\
\hline Depreciação do feminino & 19 & $30,1 \%$ \\
\hline Mercantilização corpo das mulheres & 7 & $11,1 \%$ \\
\hline Desconsideração do Estatuto Criança e Adolescente & 6 & $9,5 \%$ \\
\hline Reforço à gordofobia & 5 & $7,9 \%$ \\
\hline Reforço ao racismo & 2 & $3,1 \%$ \\
\hline Estímulo à guerra entre sexos & 1 & $1,6 \%$ \\
\hline
\end{tabular}

Fonte: elaboração própria

Nessa direção, vale destacar que cada classificação de argumento utilizada pela relatoria do Conar, expressa semanticamente a comunicação de ideias a que se prestam as peças publicitárias: "Conteúdo deseducativo e desrespeitoso" (presente em $71 \%$ dos processos), "Associação inadequada sobre mulheres" (52,4\%), "Apelo excessivo à sensualidade" (39,7\%), "Incentivo ao comportamento machista" (38\%) e Depreciação do feminino (30\%).

Uma outra dimensão identificada nas denúncias se refere aos tipos de produtos que mais recebem queixas. Neste item, identificou-se uma visível preponderância de três segmentos: "Bebidas alcoólicas", "Automobilístico" e "Alimentício”. Esses, somados, são responsáveis por quase a metade das denúncias $(49,2 \%$ da amostra). A Tabela 2 traz os percentuais que detalham que tipos de produtos são recorrentes como alvos das denúncias.

Tabela 2 - Tipos de produtos mais denunciados (\% de ocorrências nos processos da amostra

\begin{tabular}{|l|c|}
\hline \multicolumn{1}{|c|}{ Tipo de produto } & $\%$ dos processos \\
\hline Bebidas alcoólicas & $25,4 \%$ \\
\hline Automobilístico & $12,7 \%$ \\
\hline Alimentício & $11,1 \%$ \\
\hline Cosméticos (maquiagem, perfumaria, esmalte) & $6,3 \%$ \\
\hline Medicamento & $6,3 \%$ \\
\hline Erótico & $4,8 \%$ \\
\hline Telefonia & $4,8 \%$ \\
\hline Material de limpeza & $4,8 \%$ \\
\hline
\end{tabular}

\footnotetext{
${ }^{2}$ Um mesmo processo pode conter mais de um tipo de denúncia simultaneamente, por isso, os valores da tabela não devem ser somados e sim observados como ocorrências.
} 


\begin{tabular}{|l|l|}
\hline Esportes & $3,2 \%$ \\
\hline Festas & $3,2 \%$ \\
\hline Eletrodomésticos & $3,2 \%$ \\
\hline Material de Construção & $3,2 \%$ \\
\hline Auto-promoção & $3,2 \%$ \\
\hline Preservativos & $1,6 \%$ \\
\hline Vestimentas & $1,6 \%$ \\
\hline Brinquedos & $1,6 \%$ \\
\hline Banco financeiro & $1,6 \%$ \\
\hline Clube social & $1,6 \%$ \\
\hline
\end{tabular}

$(\mathrm{N}=63)$

Fonte: elaboração própria

Os dados corroboram as tendências de denúncias nas peças publicitárias que criticam a mercantilização dos corpos das mulheres associada ao status de bens materiais e seu simbolismo, principalmente em torno de veículos automotivos; exploração da sensualidade que "reforça" o corpo das mulheres vinculado ao consumo masculino de álcool; e o lugar "privado" das mulheres vinculando-as ao consumo de produtos alimentícios, posicionando o feminino ao lar e aos afazeres domésticos como horizonte de perspectivas "mais apropriadas", para mulheres.

Nominalmente, embora haja uma diversidade de empresas denunciadas, pudemos também perceber que algumas corporações aparecem com alguma frequência destacável e isso converge com os tipos de produtos que mais são mencionados em denúncias. Separamos as 8 empresas mais denunciadas nos processos e a Cervejaria Petrópolis, Leo Burnett, Ambev, $Y \& R$, Almap/BBDO, Brasil Kirin, F/Nazca e Fiat são aqueles que somaram de 3 a 6 denúncias em processos no Conar sobre a temática da pesquisa, conforme podemos ver o detalhamento da Tabela 3:

Tabela 3: Lista com as oito empresas, marcas mais denunciadas

\begin{tabular}{|l|c|}
\hline \multicolumn{1}{|c|}{ Nome da empresa } & $\mathbf{N}^{\mathbf{0}}$ de processos \\
\hline Cervejaria Petrópolis & 6 \\
\hline Leo Burnett & 6 \\
\hline Ambev & 5 \\
\hline Y \& R & 5 \\
\hline Almap/BBDO & 4 \\
\hline Brasil Kirin & 4 \\
\hline F/Nazca & 3 \\
\hline Fiat $\quad(\mathrm{N}=63)$ & 3 \\
\hline \multicolumn{2}{|c|}{ Fonte: elaboração própria } \\
\hline
\end{tabular}


Dentre os tipos de veículos que mais são alvos de processos no Conar, referente à questão da mulher, a TV é claramente o meio mais citado. A TV é mencionada em mais da metade dos processos, especificamente $61 \%$ da amostra estudada. O segundo tipo de veículo mais mencionado é a internet, ainda assim, em um percentual de ocorrência mais baixo: 37,2 $\%$ das denúncias. Revista impressa aparece em 14,5\% dos processos; Outdoor, 11,2\% e, por último, formam o último grupo de veículos mais citados nas ações, como podemos ver na Tabela 4.

Tabela 4: Tipos de veículos mais mencionados (\% sobre o total de processos da amostra)

\begin{tabular}{|l|c|}
\hline \multicolumn{1}{|c|}{ Tipo de veículo } & \% dos processos \\
\hline TV & $61,3 \%$ \\
\hline Internet & $37,2 \%$ \\
\hline Outdoor & $11,2 \%$ \\
\hline Ponto de venda & $4,8 \%$ \\
\hline Jornal Impresso & $1,6 \%$ \\
\hline Outro & $1,6 \%$ \\
\hline
\end{tabular}

Fonte: elaboração própria

$(\mathrm{N}=63)$

A efetivação de uma denúncia se dava, a passo que o Conar abria avaliação para aquela denúncia, normalmente dividida entre Conselheiros (as) componentes do órgão, registrados nos processos, como relatores (as). Quanto à origem da denúncia, os processos registram os seguintes tipos de denunciantes: (a) homem (denunciante individual do gênero masculino); (b) mulher (denunciante individual do gênero feminino); (c) indivíduos mistos (denunciantes individuais de ambos os gêneros, com homens e mulheres denunciando individualmente); (d) grupo de mulheres (denúncia coletiva que envolve mais de uma mulher); (e) grupo de homens (denúncia coletiva que envolve mais de um homem); (f) empresa; (g) Conselho Superior do Conar; (h) Sociedade Civil Organizada (associação, ONG, entidades civis etc.), conforme detalha o Gráfico 1. 
Gráfico 1 - Tipos de autores de denúncias presentes nos processos (\% de ocorrência de denunciantes nos processos analisados, sendo que um mesmo processo pode conter mais de um tipo de denunciante, por isso, os percentuais ultrapassam 100\%)

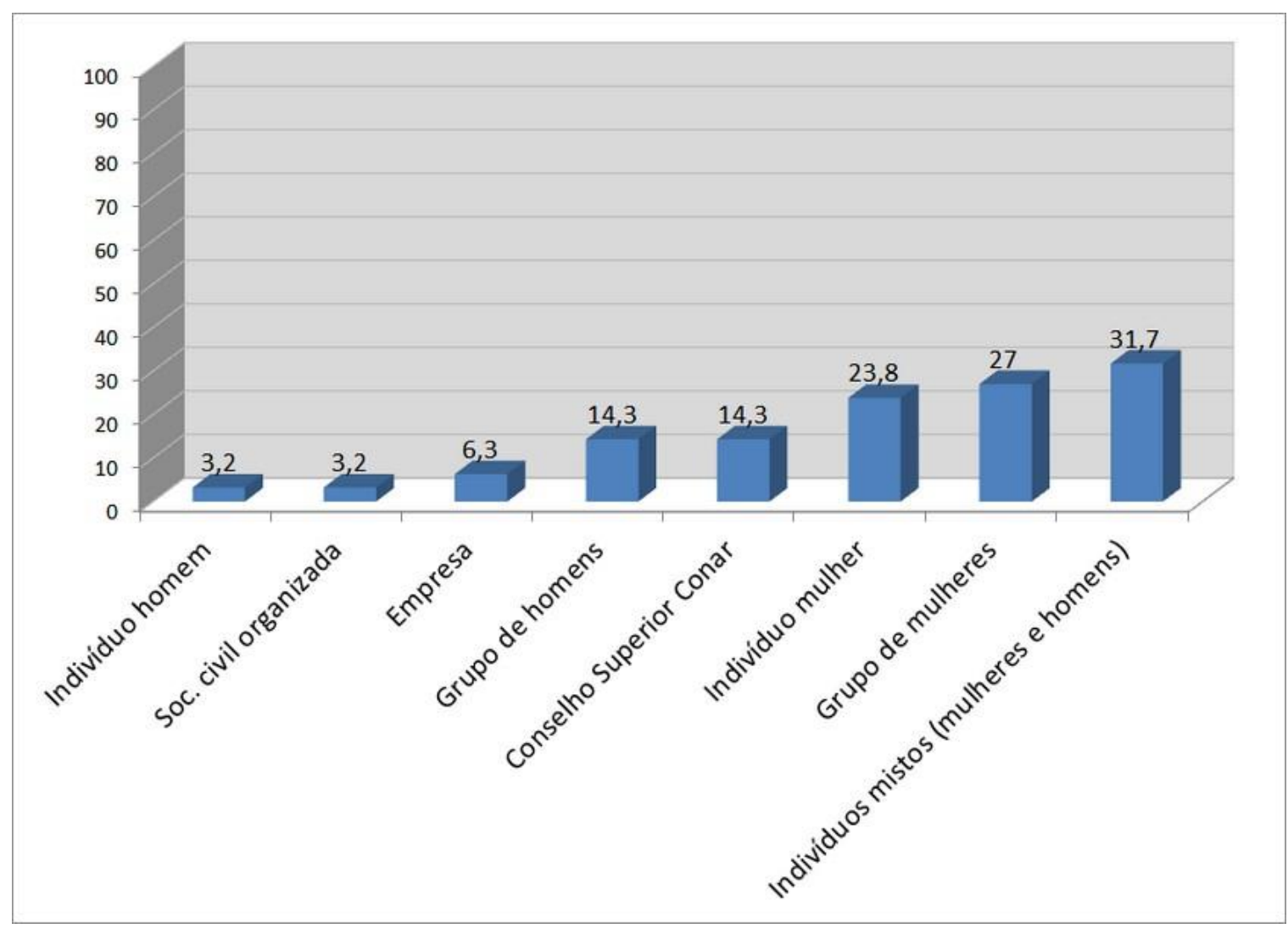

$(\mathrm{N}=63)$

Fonte: elaboração própria

Como podemos perceber nos dados (Gráfico 1), os três tipos de denunciantes que mais aparecem nos processos envolvem mulheres, sendo dois desses exclusivamente de mulheres ("Indivíduo mulher" e "Grupo de mulheres"). Os dois tipos de denunciantes que menos ocorrem são "homens individualmente" e "organizações da sociedade civil". Isso demonstra que as mulheres, entes diretamente afetados, são mais ativas no papel de denunciante e que a ação de entidades formais é menos comum nos processos.

\subsection{Características de tramitação dos processos}

Do ponto de vista do trâmite dentro da estrutura do Conar, as denúncias que tratam do tema "Mulher e propaganda" são direcionadas principalmente para três (das 9) Câmaras receptoras que constituem a organização interna do Conselho. Cerca de $76 \%$ dos processos seguem especificamente para as $1^{\mathrm{a}}, 2^{\mathrm{a}}$ e $6^{\mathrm{a}}$ Câmaras Receptoras. 
Quanto ao volume anual de processos, a média no período estudado foi de 15,7 processos julgados anualmente pelo Conar sobre o tema "Mulher e propaganda". Esta média esconde algumas diferenças relevantes. Nos quatro anos estudados (2006, 2007, 2015 e 2016) detectamos diferenças com maior volume para os anos mais recentes. Em 2006 houve 12 processos julgados; em 2007 esse volume foi de 9 processos. Na segunda parte da amostra, já na década seguinte, em 2015 houve o registro de 23 processos. Ou seja, somente em 2015 houve mais processos que 2006 e 2007 somados. Em 2016 o volume também é bem maior que a soma desses dois anos anteriores (2006 e 2007) com 19 processos. Isso mostra uma tendência de aumento de denúncias no decorrer do tempo, pelo menos no recorte temporal estudado e o ano de 2015 como um ano de maior movimentação de ações no Conar sobre o tema.

O tempo de tramitação dos processos geralmente varia de 3 a 4 meses e este tempo é bastante uniforme no recorte temporal analisado. Durante essa tramitação, a atuação de homens na atividade de relatoria do Conar, ocorre em pelo menos $62 \%$ dos processos estudados (seja como relator individual ou como relator em comissão mista), conforme podemos observar na soma dos números do Gráfico 2:

Gráfico 2 - Ocorrência de homens e mulheres atuando nas relatorias

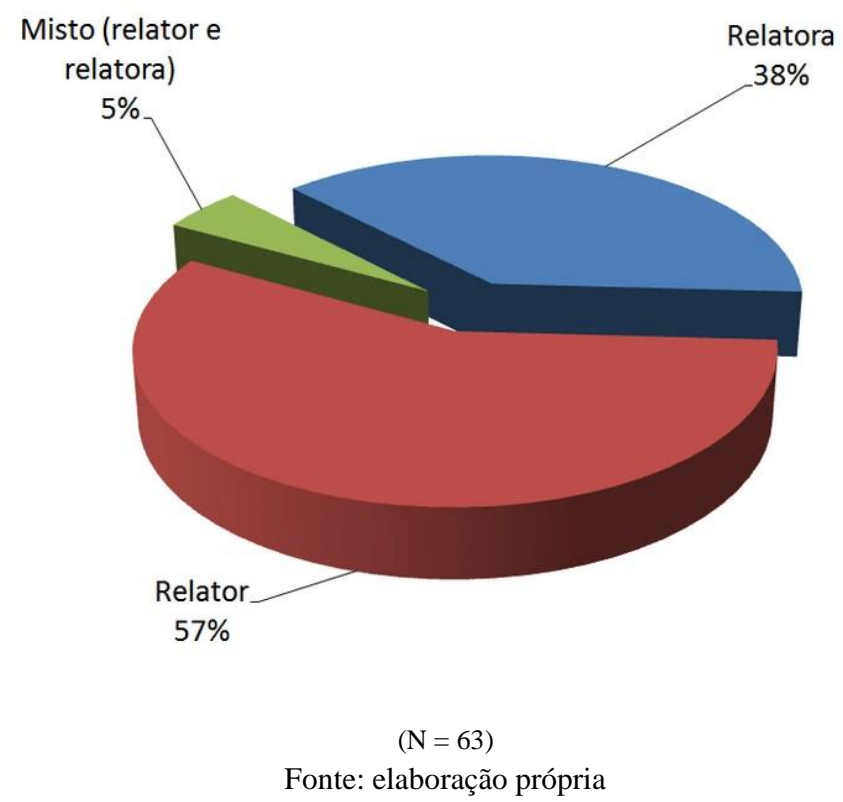

As mulheres, como relatoras individuais estão em $38 \%$ da amostra e, se somarmos a sua presença em comissões mistas de relatoria, esse índice fica em $43 \%$ dos processos. Então 
podemos concluir que há uma tendência de maior presença masculina no julgamento preliminar do processo, a título de relatoria e que não há uma priorização da indicação de relatorias de mulheres para este tipo de temática.

As relatorias são elaboradas por membros do Conar e são instrumentos importantes nos processos do órgão, pois são os relatores ou relatoras que apontarão as tendências do julgamento, principalmente através dos mecanismos da "Confirmação da denúncia": trata-se de uma espécie de parecer prévio da relatoria que é levado para o julgamento e que versa sobre as bases argumentadas pela queixa registrada. Essa "Confirmação da denúncia" pelo relator implica em indicar ao Conselho entre os encaminhamentos denominados como "Aceitar", "Negar" ou "Estar parcialmente de acordo" com os termos da denúncia. A confirmação negativa não interrompe a tramitação do processo que segue para ser julgado. Sobretudo, marca a posição do relator e a sua indicação ao Conselho e o processo segue adiante.

Dito isso, o que podemos observar no Gráfico 3 é que cerca de 57\% dos processos tem a confirmação da denúncia negada pela relatoria; outros $35 \%$ são aceitas; e outros $8 \%$ são parcialmente aceitos/negados.

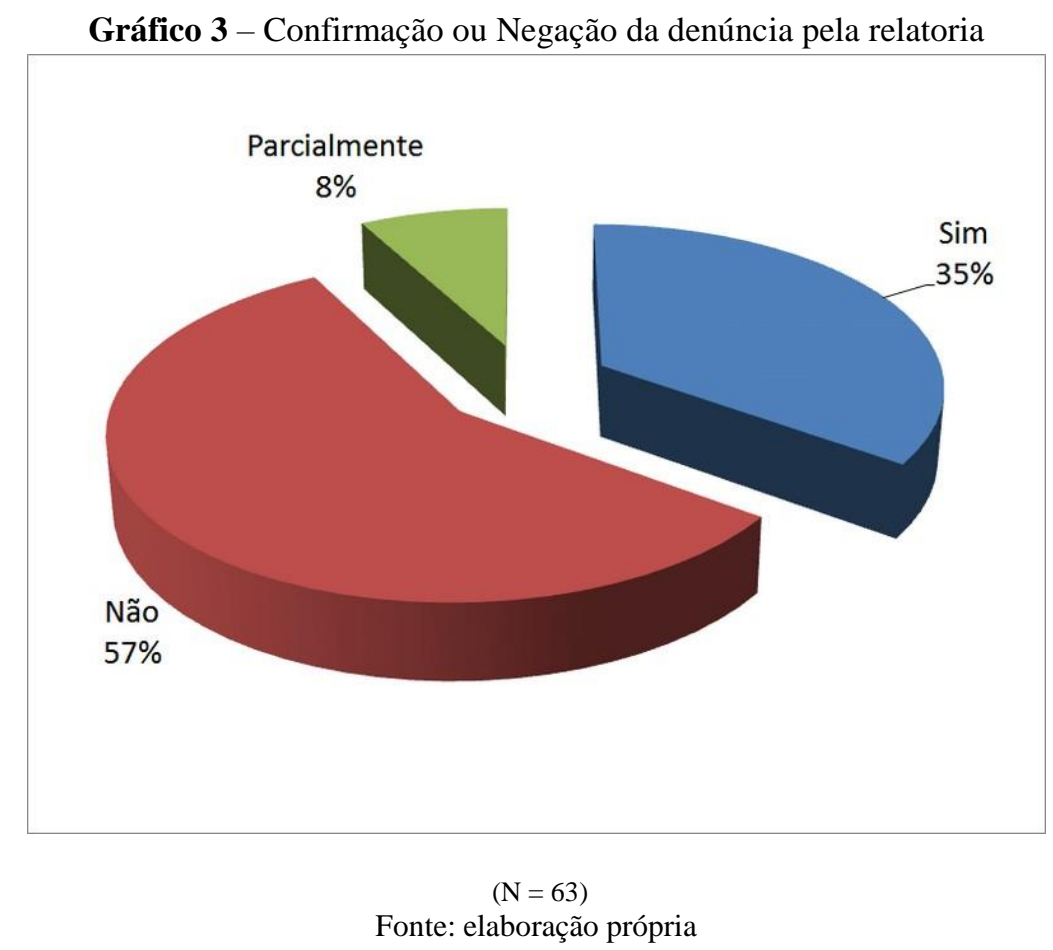

Embora a negação da denúncia não signifique o fim do andamento do processo (que continua a tramitar independente da negação ou confirmação da mesma pelo relator) o que 
pudemos detectar nos dados é que isso tem uma forte relação com o resultado do julgamento final dos processos: trata-se de um forte indicador que a denúncia será arquivada. Todos os casos cuja confirmação da denúncia foi qualificada como negativa obtiveram ao final do julgamento o "Arquivamento", sendo a "Inexistência de irregularidade" o argumento mais presente nessas sentenças (utilizado em $95 \%$ das sentenças de casos de que tiveram como procedente a confirmação da denúncia negativa).

Os resultados demonstram que, proporcionalmente, há uma tendência de maior aceitabilidade da denúncia quando a relatoria é exercida por mulheres em comparação aos processos relatados por homens. Cerca $50 \%$ das denúncias relatadas por mulheres foram aceitas ou parcialmente aceitas contra cerca de $33 \%$ no caso de exercidas por homens. Por isso, a predominância de homens na relatoria tende a ser um elemento importante no processo.

Também observamos como ocorre a distribuição de gênero pelas relatorias do Conar nas 3 principais câmaras receptoras, responsáveis por grande parte dos processos sobre a temática deste estudo. Observemos a Tabela 5:

Tabela 5 - Distribuição de relatorias entre homens, mulheres e mista nas $1^{\mathrm{a}}, 3^{\mathrm{a}}$ e $6^{\mathrm{a}}$ Câmaras receptoras

\begin{tabular}{|l|r|r|r|}
\hline Gênero da relatoria & $\mathbf{1}^{\mathbf{a}}$ Câmara & $\mathbf{2}^{\mathbf{a}}$ Câmara & $\mathbf{6}^{\mathbf{a}}$ Câmara \\
\hline Relatora & $31,3 \%$ & $45,5 \%$ & $50 \%$ \\
\hline Relator & $62,5 \%$ & $50,0 \%$ & $50 \%$ \\
\hline Relatores (as) (misto) & $6,3 \%$ & $4,5 \%$ & $\begin{array}{r}\text { Sem } \\
\text { ocorrência }\end{array}$ \\
\cline { 2 - 4 } & $\mathrm{N}=16$ & $\mathrm{~N}=22$ & $\mathrm{~N}=10$ \\
\hline
\end{tabular}

(Fonte: elaboração própria)

Como podemos notar, as $2^{\mathrm{a}}$ e $6^{\mathrm{a}}$ Câmaras têm mais ou menos o mesmo padrão em termos de distribuição das relatorias para "relatoras" (isto é, relatoria exercida exclusivamente por uma mulher): em média, a metade dos relatores é do gênero feminino. No caso da $1^{\mathrm{a}}$ Câmara há uma diferença relevante na ocorrência de relatorias exclusivas de mulheres: isso cai para 31,3\% dos processos. Isso demonstra que (a) não há nenhum indicativo de que denúncias que envolvem a temática da "mulher" sejam distribuídas preferencialmente para relatoras, isto é, para mulheres tendo em vista a premissa de que estariam em melhor perspectiva para analisar os casos e julgar; (b) em algumas Câmaras prevalece, inclusive, mais homens neste tipo de relatoria. 


\subsection{Características dos julgamentos e seus resultados}

No Conar, um processo pode ter os seguintes desfechos: (a) "Arquivamento"; (b) "Advertência"; (c) "Sustação"; (d) "Alteração". O arquivamento ocorre quando o processo foi julgado e o mérito da acusação negado, sem penalidades aplicadas. A sustação significa a decisão por suspender a circulação da peça, na forma em que se apresentou, quando da denúncia ou queixa realizada ${ }^{3}$. A advertência implica em informar à agência e empresa envolvidas na criação e veiculação da peça publicitária, que precisam se adequar com mais atenção ao compromisso da publicidade de ser confiável no conteúdo e honesta na apresentação, pela relação de confiança pública que incide em seu êxito. Por fim, uma última penalidade aplicável é a alteração da peça, que acarreta em recomendação, que tem força de exigência, para que a peça publicitária em questão altere sua forma, conteúdo e apresentação.

Boa parte das peças publicitárias arroladas sobre mulher e propaganda (64\%) tem a denúncia arquivada ao final do julgamento pelo Conar. Dentre os outros cerca de 1/3 que obtiveram algum tipo de condenação temos as seguintes ocorrências de penalidades: $27 \%$ receberam a penalidade de sustação; $6 \%$ de alteração da peça e 3\% de Advertência, como podemos visualizar no Gráfico 4:

Gráfico 4 - Resultado dos julgamentos

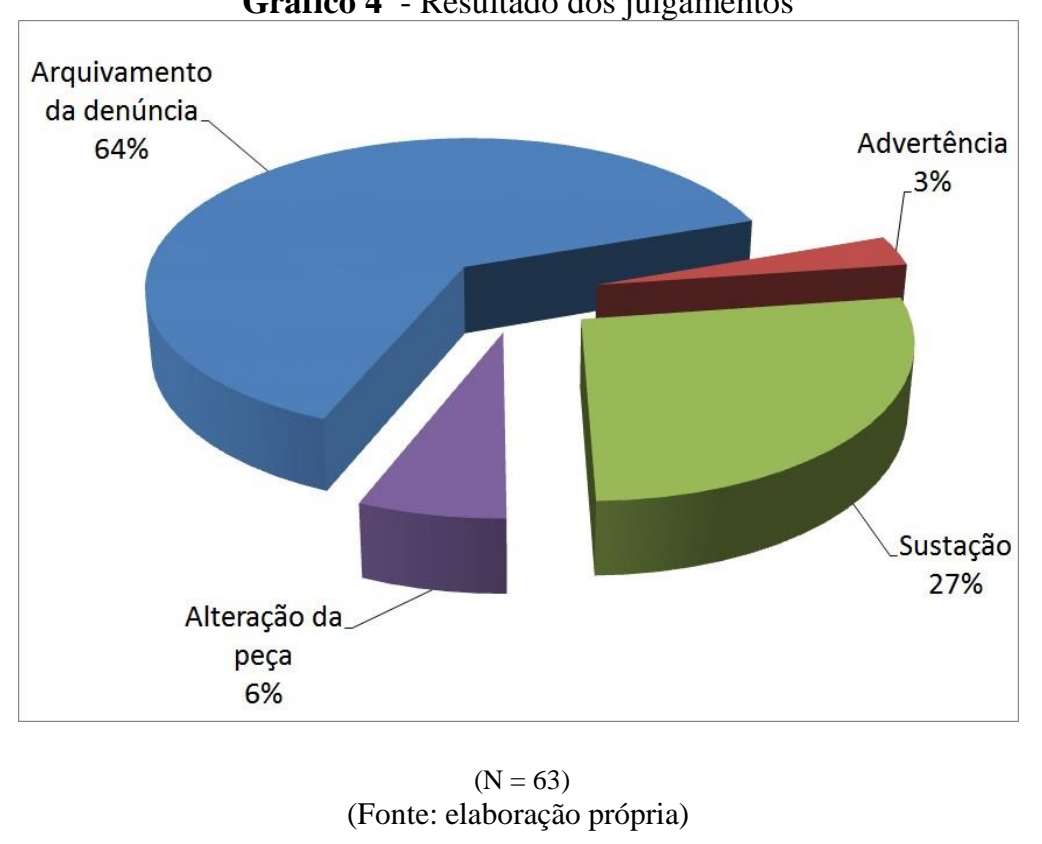

\footnotetext{
3 A sustação está associada à discordância com o artigo $6^{\circ}$ do CBAP - Código Brasileiro de Autorregulamentação Publicitária, que informa: "Toda publicidade deve estar em consonância com os objetivos do desenvolvimento econômico, da educação e da cultura nacionais. “
} 
Nota-se que, quando há algum tipo de condenação, prepondera a pena de sustação (se isolarmos apenas o universo de processos que obtiveram algum tipo de penalidade, $75 \%$ dos casos foram de sustação). A ocorrência de processos que resultem em penalidade de Alteração da peça ou penalidade de Advertência é bem mais rara.

Ao analisarmos os resultados dos processos por Câmara Receptora, especificamente olhando para as $1^{\mathrm{a}}, 3^{\mathrm{a}}$ e $6^{\mathrm{a}}$ (que juntas abarcam $76 \%$ das denúncias sobre o tema), temos o seguinte quadro de ocorrências (Tabela 6):

Tabela 6 - Resultados e penalidades aplicadas por Câmara Receptora ( $1^{\mathrm{a}}, 3^{\mathrm{a}}$ e $6^{\mathrm{a}}$ Câmaras receptoras)

\begin{tabular}{|l|r|r|r|}
\hline \multicolumn{1}{|c|}{ Resultado do processo } & $\mathbf{1}^{\mathbf{a}}$ Câmara & $\mathbf{2}^{\mathbf{a}}$ Câmara & $\mathbf{6}^{\mathbf{a}}$ Câmara \\
\hline Arquivamento da denúncia & $62,5 \%$ & $72,7 \%$ & $30,0 \%$ \\
\hline Advertência & Sem ocorrência & $4,5 \%$ & $10,0 \%$ \\
\hline Sustação & $31,3 \%$ & $13,6 \%$ & $50,0 \%$ \\
\hline Alteração da peça & $6,3 \%$ & $9,1 \%$ & $10,0 \%$ \\
\hline \multirow{2}{*}{$(\mathrm{N}=16)$} & $(\mathrm{N}=22)$ & $(\mathrm{N}=10)$ \\
\hline
\end{tabular}

(Fonte: elaboração própria)

Nesta tabela, duas questões que merecem destaque: (a) nos períodos pesquisados, a $1^{\text {a }}$ Câmara não aplicou em nenhum processo a penalidade de "Advertência". Aparentemente, nesta Câmara, há uma tendência deste tipo de pena não ser executada; (b) a $6^{\mathrm{a}}$ Câmara tem um padrão diferente das demais: enquanto na $1^{\mathrm{a}}$ e $2^{\mathrm{a}}$ Câmara prevalecem como resultado o arquivamento da denúncia (cerca 60 a 70\%, que também um padrão do total da amostra), a $6^{\text {a }}$ Câmara tem uma baixa ocorrência de arquivamento que fica em torno dos $30 \%$ dos processos sendo que metade (50\%) dos processos recebem a penalidade de "Sustação". Isso demonstra que as Câmaras receptoras nem sempre operam de modo uniforme, pois algumas podem ter padrões bastante diferentes de desfecho dos julgamentos.

Quanto às justificativas utilizadas nas sentenças, seja aquelas com penalidades ou seja aquelas arquivadas, cerca de $62 \%$ dos processos citam o Regimento Interno do Conselho de Ética (RICE) para embasar a decisão e $38 \%$ citam a ou do Código Brasileiro de Autorregulamentação Publicitária (CBAP). Nas sentenças finais emitidas pelo Conar, os argumentos centrais mais comuns são: "Não vê irregularidade", presente em $62 \%$ dos

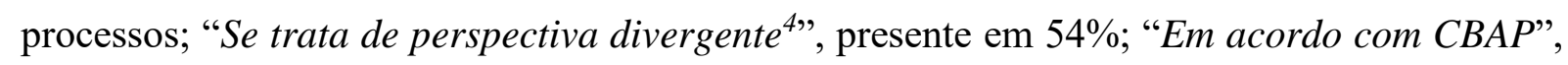

\footnotetext{
${ }^{4}$ A afirmação "Se trata de perspectiva divergente" está associada ao entendimento de discordância de opinião, diante da interpretação da intenção da criação da mensagem. Onde tanto a defesa da peça publicitária, quanto a relatoria do Conar concordam entre si e alegam como devolução da queixa que houve, por parte do (a) consumidor (a), equívoco de interpretação da ideia original da mensagem.
} 
encontrado em $44 \%$ das sentenças finais. A tabela 7 traz um maior detalhamento das ocorrências de outros argumentos nas sentenças:

Tabela 7 - Argumento central da sentença mais recorrentes

\begin{tabular}{|l|c|}
\hline \multicolumn{1}{|c|}{ Argumento da sentença } & $\begin{array}{c}\text { \% de processos nos quais os } \\
\text { argumentos foram utilizados }\end{array}$ \\
\hline Não vê irregularidade & $62 \%$ \\
\hline Se trata de perspectiva divergente & $54 \%$ \\
\hline Em acordo com CBAP & $44 \%$ \\
\hline Incentiva o desrespeito às mulheres & $37 \%$ \\
\hline Em desacordo com CBAP & $32 \%$ \\
\hline Em desacordo com a CF (Constituição Federal) & $24 \%$ \\
\hline Se refere a humor & $22 \%$ \\
\hline Impossibilidade de julgamento & $3 \%$ \\
\hline \multicolumn{2}{|c}{$(\mathrm{N}=63)$} \\
\end{tabular}

Fonte: elaboração própria

O registro da queixa pede identificação pessoal de quem reclama, chamado pelo Conar de "consumidor". É necessário informar dados como: nome; documento de identidade; $e$ mail; endereço; cidade; unidade federativa (estado); contato telefônico; escolaridade; idade; relato do produto ou serviço anunciado; veículo de comunicação; onde está veiculada a peça; e motivo da queixa. A plataforma oferece ainda a possibilidade de se anexar arquivos de no máximo $5 \mathrm{Mb}$ de tamanho, que devem ser imagens ou arquivos no formato PDF.

Para visualizarmos, a título de exemplificação, como os argumentos são encadeados, podemos tomar como base o processo 044-15, julgado em julho de 2015. Nesta ação temos tanto os argumentos de denunciantes (que alegaram postura de objetificação das mulheres), quanto o posicionamento do relator em recusar a queixa e, contrariamente, também temos a posição de uma relatora, ao ponderar sobre a necessidade de se considerar à realidade de que a peça em questão:

Reclamação denunciante 1 :

Motivo: O motivo da reclamação é sobre o anúncio misógino, machista, ofensivo que a Itaipava faz de sua cerveja mostrando uma mulher como objeto e mostrando que homens podem sim assediarem verbalmente que isso é engraçado. Este comercial deve ser retirado do ar pelo incentivo que faz ao abuso de mulheres (processo 044-15).

Reclamação denunciante 2:

Motivo: Esta propaganda é um desrespeito para todas as mulheres e principalmente quem trabalha de garçonete em bares. A mulher está trabalhando e nesta cena aparece um desrespeito ao trabalhador. As pessoas 
vêem essa propaganda e muitas vezes querem fazer aquilo também com as atendentes que estão trabalhando, podendo ser esposas, mães de família e nossas filhas. Existem muitas propagandas que mostram desrespeito e a não obediência das leis, exemplo propagandas de carros e altas velocidades, manobras bruscas. Existem propagandas de novelas com cenas indecentes nos intervalos de desenhos infantis da rede Globo. Quando vão dar um basta nisso. Por várias vezes me constrangi diante da minha filha de 6 anos, num intervalo de um filme infantil a tarde e no intervalo cenas de novela, de uma filha xingando um pai, ou agredindo, ou cenas de "quase" sexo na TV. Obrigado. Espero pelo menos uma resposta sobre esta reclamação. Obrigado (processo 044-15).

Reclamação denunciante 3:

Motivo: Gostaria de denunciar o comercial "o verão chegou" da cerveja Itaipava pois é explícita a agressão ao gênero feminino tratando a mulher como objeto e incentivando a agressão verbal e assédio por parte dos homens, espero que essa reclamação tenha efeito, pois vemos esses tipos de comerciais diariamente na televisão! O desrespeito com a mulher se tornou banal! Esse comercial mostra mulheres como uma mercadoria!!!!! Somos seres humanos e precisamos de respeito!!!!! (processo 044-15)

A seguir, têm-se a transcrição dos trechos que trazem a defesa da agência e da cervejaria:

Com isso, não identifico no presente anúncio um tratamento desrespeitoso com relação à mulher. Muito pelo contrário, os atributos femininos no caso são tratados de forma a ressaltar a beleza da protagonista de forma relativamente sutil, prevalecendo o bom humor no uso criativo do trocadilho "Vera-Verão" (processo 044-15).(...) Até mesmo porque o objetivo principal desta campanha é o humor, considerando uma das ferramentas mais efetivas na criação do vínculo entre produto e consumidor. $E$ nesse aspecto, desde que explorado de forma responsável e ética, jamais poderia ser alijado da campanha, por encontra-se dentro do chamado princípio da liberdade de criação e expressão publicitária. (sem ênfase no original) (processo 044-15)

Por fim, temos o resultado do julgamento da relatoria do Conar, publicada em maio de 2015:

Arquivamento, de acordo com o artigo 27, da seção VII, do RICE Regimento Interno do Código de Ética do Conar, que propõe: “Artigo 27 O relatório conterá o resumo dos fatos, das principais peças dos autos e das provas neles produzidas; destacará, caso tenha ocorrido, a concessão de medida liminar; e, em parecer fundamentado, recomendará, conforme o caso: I - O Arquivamento da representação quando: a - julgar não caracterizada infração ao Código Brasileiro de Autorregulamentação Publicitária; b - julgar prejudicada a representação ou recurso, em razão da perda de seu objeto; c - tenha havido expressa desistência dos autores, dispensada a audiência da parte contrária; d - tenha havido, documentadamente, a conciliação das partes (processo 044-15). 
$\mathrm{Na}$ mesma data, houve registro de voto contrário de relatora que pondera com as seguintes argumentações:

Registro de Voto divergente.Adoto relatório de fis, mas divirjo do parecer no tocante ao desfecho. Para o Relator, a publicidade pode usar como técnica a associação do produto a outros valores e, no caso, a mulher, para despertar o desejo de consumo. Entretanto, reputo excessiva a exploração da figura feminina e, mais especificamente, da figura do corpo da mulher como apelo central e único para a divulgação da cerveja que, diga-se de passagem, chega a ficar secundária nos anúncios. Por tais motivos considero que o caso merece, ao menos, a adoção da medida de advertência aos responsáveis. Fundamento: artigos $6^{\circ}$ e 50, letra 'a', Anexo "P”, no 1 e 3, letra 'a', todos do Código Brasileiro de Autorregulamentação Publicitária (processo 044-15).

Ainda sobre objetificação dos corpos femininos, onde a violência do discurso heteronormativo compulsório ${ }^{5}$ se dá nas práticas sociais e políticas, inclusive em ambientes profissionais, em que o assédio sexual é interpretado como mais um exagero das vítimas, no processo de número 231, do ano 2013, intitulado "Tema Propaganda", a relatoria do Conar não viu irregularidade na narrativa apresentada pelo anúncio e negou haver perspectiva abusiva. Conforme se apresenta no resumo e na justificativa do conselheiro do órgão que fez a relatoria do processo e decidiu por arquivá-lo por improcedência da denúncia:

Resumo da denúncia feita pelo relator do Conar:

Anúncio da agência de propaganda Tema, veiculado em mídias sociais, atraiu reclamações de cinco consumidores, residentes em Vitória (ES), São Paulo (SP), Fortaleza e Juazeiro do Norte (CE), que o consideraram desrespeitoso e discriminatório. A campanha trazia o título: "Redator procura diretora de arte charmosa, cheirosa e talentosa. Ok, se você for um diretor de arte talentoso e com experiência, também serve. " Em sua defesa, a agência, que tem sede na cidade de Vitória, alegou uso de linguagem coloquial, dirigida a publicitários, sem possibilidade ofensiva a qualquer pessoa. (processo 231-13).

Ao propor arquivamento da denúncia, a relatoria do Conar não só considerou não haver irregularidade no anúncio, como registrou desrespeitoso juízo de valor sobre a queixa de publicidade abusiva, ironizando a inteligência e o incômodo dos consumidores, conforme trecho abaixo extraído do resumo disponível no site do Conar:

Tolher a liberdade de criação de um anúncio como esse é admitir que a publicidade politicamente correta deva fazer parte do nosso cotidiano. Seria,

\footnotetext{
${ }^{5}$ Conceito apresentado pela professora e escritora estadunidense Adrienne Rich, na década de 1980, no ensaio intitulado "Heterossexualidade compulsória e existência lesbiana", e posteriormente adotado por feministas, em que o entendimento das mulheres como seres naturalmente heterossexuais, é questionado e visto como tentativa de imposição de uma conformação única da sexualidade humana e consequente marginalização de outras orientações sexuais existentes.
} 
como um tiro no pé, um convite à chatice e à conclusão de que nossos consumidores não têm inteligência suficiente para discernir o exagero do humor daquilo que efetivamente se configura desrespeito (processo 231-13).

Este conjunto de argumentos contidos nestes exemplos (processos 044-15 e 231-13 ) demonstram diferentes visões sobre o que se compreende como "humor" e também dificuldade em reconhecer o conceito de objetificação da mulher nitidamente vinculada à propaganda, conforme descrito pelas denúncias. Também demonstra que as decisões do Conselho nem sempre são homogêneas. Isto é bastante recorrente na amostra estudada e nos ajuda a visualizar melhor a tendência do discurso e de argumentações textuais que aparecem por trás dos dados aqui apresentados.

\section{CONSIDERAÇÕES}

Este artigo teve como objetivo caracterizar como o Conar tem lidado com as denúncias e respectivos processos que tratam de imagem das mulheres veiculadas em propagandas no Brasil. Primeiramente, versamos sinteticamente sobre os debates que envolvem teorias feministas, conceitos de gênero e de como a comunicação se insere neste contexto, sobretudo através da publicidade de produtos e serviços. Buscamos demonstrar que a objetificação da mulher na propaganda não é apenas um problema superficial ou abstrato, pois envolve a construção de realidades, valores e também pode culminar em diferentes formas de violência na prática.

No tocante à caracterização das denúncias, os dados demonstraram que a TV é o meio mais citado nos processos. Ao mesmo tempo, é possível identificar uma provável tendência em posicionar a internet com destaque, já ocupando o segundo lugar enquanto tipo de veículo mais mencionado.

O volume das denúncias demonstrou que a média anual (de 15,7 processos) significa que há, também em média, 1 denúncia por mês. Ao olharmos o dado mais detalhadamente também pudemos também notar que houve um aumento do volume de denúncias nos anos mais recentes do recorte temporal, e isso nos permite levantar a hipótese de que estaria ocorrendo um crescimento de possíveis violações ou, pelo menos, a percepção destas (e não uma diminuição). Outros estudos longitudinais com amostras mais longas podem confirmar ou não esta hipótese. 
O fato das denúncias apontarem recorrentemente violações como "Conteúdo deseducativo e desrespeitoso", "Associação inadequada sobre mulheres", "Apelo excessivo a sensualidade", "Incentivo ao comportamento machista" $e$ "Depreciação do feminino" é um indicativo de que ainda prevalece em muitas peças publicitárias determinadas concepções patriarcais ou machistas em suas bases. Também o fato de três segmentos - "Bebidas alcoólicas", "Automobilístico" e "Alimentício" - serem responsáveis por quase a metade das denúncias também indica que tais produtos têm apelado para o consumo masculino (como bebidas e automóveis) utilizando a imagem objetificada da mulher; e produtos alimentícios tem reforçado o lugar da mulher como o espaço doméstico.

A concentração de oito empresas mais citadas presentes em quase $60 \%$ dos processos também é um indicativo importante, pois demonstra que um mesmo grupo de empresas parece ser recorrentemente denunciada.

$\mathrm{Na}$ tramitação dos processos dentro do Conar, os resultados demonstram que, proporcionalmente, há uma tendência de maior aceitabilidade da denúncia quando a relatoria é exercida por mulheres em comparação aos processos relatados por homens. Por isso, a predominância de homens na relatoria (também identificada na pesquisa) tende a ser um elemento importante e definidor nos processos e uma distorção a ser corrigida.

$\mathrm{O}$ fato de a maior parte das denúncias ser arquivada não nos permite julgar o mérito dos processos, mas nos permite dizer que, em geral, denúncias não serão levadas adiante pelo Conselho. De todo modo, se observarmos os conteúdos das peças denunciadas e os argumentos proferidos pelos julgamentos, é possível perceber diversas visões patriarcais embutidas e sedimentadas nos julgamentos.

No sentido do resgate histórico da construção de narrativa, onde é instituído e repetido exaustivamente o imaginário sobre papéis sociais, "cabíveis" a homens e mulheres, nota-se a necessidade de aprofundar o debate sobre gênero no âmbito interno do Conar, seja levando em conta as diversas contribuições das teorias que discutem sexo/gênero, categoria sexual, generalização do "corpo" e seu significado sexuado, seja instituindo a necessidade de incorporar mais mulheres nas relatorias do órgão e no julgamento dos processos, hoje preponderantemente exercida por homens. 


\section{REFERÊNCIAS}

ABA. Associação Brasileira de Anunciantes. Guia para Representação Responsável de Gênero na Publicidade. São Paulo, 2017. Site: http://www.aba.com.br/wp-content/uploads/2018-07-

24/5b5725b768f84.pdf. Último acesso em 27/12/2018 as 11:44.

AMARAL, Adriana; COIMBRA, Michele. Expressões de ódio nos sites de redes sociais: o universo dos haters no caso \#eunãomereçoserestuprada. Contemporânea. 13(01),p. 294-310. 2015.

BELELI, Iara. Corpo e identidade na Corpo e identidade na propaganda. Estudos Feministas, , 15(1), p. 193-215, 2007.

BIROLI, Flavia e MIGUEL, Luis Felipe. (Org.). Teoria politica feminista, hoje. In: Teoria politica feminista: textos centrais, 2013, p. 7-54.

BUTLER, Judith P. Problemas de gênero: feminismo e subversão de identidades. Rio de Janeiro: Civilização Brasileira, 2003.

CBAP. Código Brasileiro de Autorregulamentação Publicitária. São Paulo, SP: 1980.

CORNELL, Drucilla. At the heart of freedon. Princeton. Princeton University Press, 1998.

ELSHTAIN, Jean Bethke, Public man, private woman: women in social and political thought. Princeton: Princenton University Press, 1981.

ESCAVONE, Lucila.Estudos de gênero: uma sociologia feminista? In: Revista Estudos Feministas. Florianópolis, SC: UNEP, 2008.

GUIMARÃES, Fernanda Tais Brignol; OLIVEIRA, Vinicius Oliveira de. Os comerciais e a representação da mulher: a exploração do corpo e da imagem feminina na mídia. Revista Ágora, 22, p. 124-135, 2015.

GONZALEZ, Lélia e HASENBALG Carlos. Lugar de negro. Rio de Janeiro. Editora Marco Zero. 1982.KNOLL, G. Frainer. Discursos de gênero na publicidade: análise crítica de Textos publicitários em revistas. In.: Sociais e Humanas, Santa Maria, v. 25, n. 02, julho/dezembro 2012, p.239-252.

LAURETIS, Teresa. A Tecnologia do Gênero. Tradução de Suzana Funk. In:HOLANDA, Heloísa (Org.). Tendências e Impasses: o feminismo como crítica da cultura. Rio de Janeiro: Rocco, 1994.

MANO, Maíra Kubík. De um jornalismo sexista a um jornalismo com perspectiva de gênero. Lutas Sociais, 21(39), p. 9-20, 2017.

MORENO, Rachel. A imagem da mulher na mídia. São Paulo: Publisher, 2012

MIGUEL, Luis Felipe. Os meios de comunicação e a prática política. In: Lua Nova [online]. n.55-56, pp.155-184, 2002.

ORLANDI, E. P. Análise de Discurso: princípios e procedimentos. Campinas, SP: Pontes, 2001.

PATEMAN, Carole. Críticas feministas à dicotomia público/privado. In: MIGUEL, Luis Felipe; BIROLI, Flávia. Teoria política feminista: textos centrais. Vinhedo: Editora Horizonte, 2013, p. 5579.

PEREIRA, Bruna C. Jaquetto. Tramas e Dramas de Gênero e Cor: A Violência Doméstica e Familiar contra Mulheres Negras. Brasília, Brado Negro, 2016. 
SCOTT, J.W. Gender: A Useful Category of Historical Analysis. Vol. 91, N 5. New York: The American Historical Review, 1986, p. 1053-1075.

SCHEIDWEILER, Gerson; SOUSA, Janara. Gênero e Direito à Comunicação: perspectivas teóricocontextuais sobre a (in)visibilidade dos discursos feministas na esfera pública contemporânea. Texto apresentado no Intercom - $\mathbf{4 0}^{\circ}$ Congresso Brasileiro de Ciências da Comunicação da Sociedade Brasileira de Estudos Interdisciplinares da Comunicação. Curitiba, 2017. Disponível em < http://portalintercom.org.br/anais/nacional2017/resumos/R12-1885-1.pdf >

SAFFIOTI, Heleieth I.B. Contribuições feministas para o estudo da violência de gênero. Cadernos Pagu, 16, p. 115-136, 2001.

SOARES, André de Moura. A Publicidade e a Dignidade da Mulher. Portal Jurídico Investidura, Florianópolis-SC, 2008. Disponível em investidura.com.br/biblioteca-juridica/artigos/direitoconstitucional/1377-a-publicidade-e-a-dignidade-da-mulher. Último acesso 23/10/2018 às 23:00.

SOIHET, Rachel. Relações de Gênero e Formas de Violência. In: BUSTAMANTE, Regina Maria da Cunha. e MOURA. José Francisco de. (Orgs.) Violência na História. Rio de Janeiro: Mauad X: FAPERJ, 2009.

YOUNG, I. M. A imparcialidade e o Público Cívico: Algumas Implicações das Críticas

Feministas da Teoria Moral e Política. In.: BENHABIB; CORNELL (Orgs). Feminismo Como Crítica da Modernidade. Rio de Janeiro: Editora Rosa dos Tempos, 1987.

Original recebido em: 09 de outubro de 2019

Aceito para publicação em: 05 de julho de 2020

\section{Luana Ferreira Alves}

Mestre em Comunicação, na linha de Políticas de Comunicação e Cultura, pela Universidade

de Brasília (UnB). Desenvolve pesquisas na área de Comunicação, Internet e Gênero, atuando principalmente nos temas relacionados a novas tecnologias de comunicação, políticas de comunicação,

Democratização da Comunicação e Gênero. É graduada em História pela Universidade Estadual de Goiás. Pós-graduada em Ecologia pela Faculdade de Meio Ambiente e Tecnologias (FAMATEC). Atualmente é analista de Projetos do Fundo Social ELAS.

\section{Sivaldo Pereira da Silva}

Professor da Faculdade de Comunicação (FAC) e do Programa de Pós-Graduação em Comunicação da Universidade de Brasília (UnB). PhD em Comunicação e Cultura Contemporâneas pela Universidade Federal da Bahia (UFBa), com estágio doutoral na University of Washington (EUA). Coordenador do Centro de Estudos em Comunicação, Tecnologia e Política (CTPol) da UnB e pesquisador do Instituto Nacional de Ciência e Tecnologia em Democracia Digital (INCT-DD).

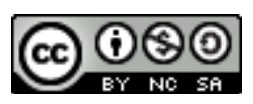

Esta obra está licenciada com uma Licença

Creative Commons Atribuição-NãoComercial-CompartilhaIgual 4.0 Internacional 